\title{
The Reconstruction Strategies of Vrisa, Greece after the 2017 Earthquake
}

\author{
Fangning Wu, Yinsheng Tian \\ School of Architecture, South China University of Technology, Guangzhou, China \\ Email: 1986508302@qq.com, arystian@scut.edu.cn
}

How to cite this paper: $\mathrm{Wu}, \mathrm{F} . \mathrm{N}$. and Tian, Y.S. (2018) The Reconstruction Strategies of Vrisa, Greece after the 2017 Earthquake. World Journal of Engineering and Technology, 6, 24-33. https://doi.org/10.4236/wjet.2018.62B003

Received: March 24, 2018

Accepted: May 19, 2018

Published: May 22, 2018

\begin{abstract}
This paper focuses on a small Greek village named Vrisa and a specific condition of Lesbos as the arrival island for hundreds of thousands of refugees, aiming to reconsider places in state of emergency and think of flexible future reconstruction strategies which are able to adapt to the new unpredictable conditions of post-disaster. After the 2017 earthquake, the buildings in Vrisa were marked with red, yellow and green which shows different levels of damage. Also, there are some regulations to restrict the façade, square meter, decoration and funding of rebuilding. By analyzing the characteristics of Vrisa village before earthquake and situation after earthquake, we came up with three reconstruction strategies from different aspects to find solutions. Meanwhile, this paper hopes to provide a reference and suggestions for similar cases of post-earthquake reconstruction.
\end{abstract}

\section{Keywords}

Earthquake, Reconstruction, Strategies, Urban Planning

\section{Introduction}

On 12 June 2017, a 6.3-magnitude earthquake struck Vrisa that a woman died and 10 people were hurt (Figure 1 and Figure 2). After the earthquake, Vrisa's historic shell has been hit decisively. The part of the settlement from Tsiarsi to the stream has been mostly hit, resulting to an almost complete destruction in this zone, while extensive disasters exist throughout the settlement but mostly in individual buildings. Only few houses in Vrisa were marked as inhabitable. Most of the inhabitants were moved and distributed to the nearby villages of Vatera and Polichnitos, in hotel resorts or empty houses. Some of the shops also reopened in those neighbour villages keeping the activities of the village alive in their new spaces. Although the school building was destroyed by the earthquake, 


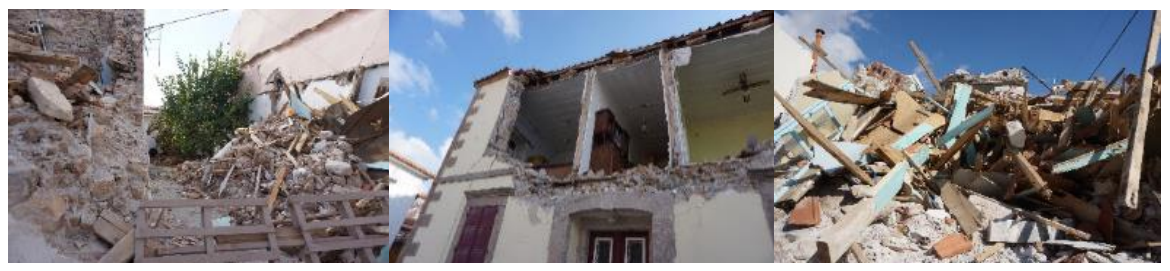

Figure 1. Vrisa after the earthquake.

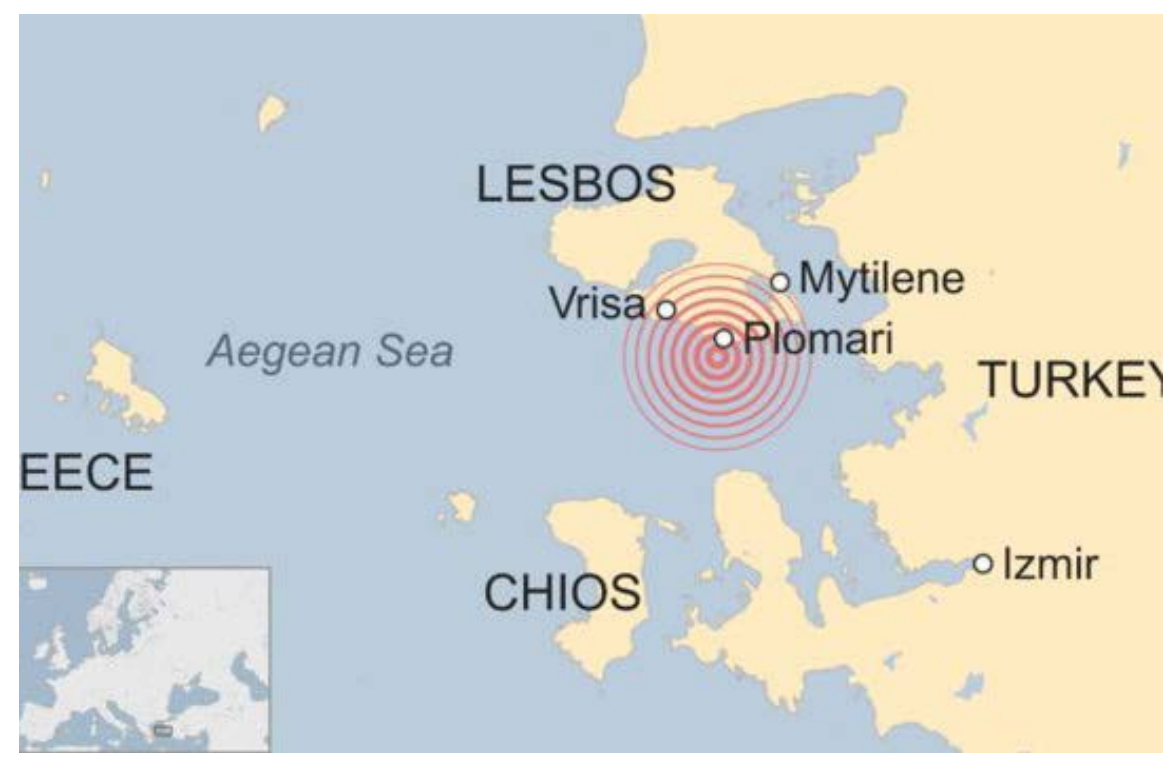

Figure 2. Earthquake in Lesbos, June 2017.

the function of the school moved in containers temporarily at the same spot of the village. Due to the architectural value of Vrisa, the discussion at the moment concerning the reconstruction of the village focuses on what level the houses should be rebuilt exactly the same as they were before. In an attempt to preserve the volumes and analogies of the former settlement, a new regulation defines the rebuilding of each house in a minimum of $75 \%$ of its total square meters.

This article specifically aims to analyse the present situation of Vrisa and put forward some reconstruction strategies to help activating this village. It can provide guidelines for places in condition of post-disaster and give some inspired suggestions [1] [2].

\section{Characteristics of the Socio-Economic Context before the Earthquake}

The village of Vrisa is located in the south of Lesbos, at a distance of $32 \mathrm{~km}$ west-southwest of the city of Mytilene (road distance $47 \mathrm{~km}$ ). The distance of Vrisa from the nearest beach, (the beach of Vatera) is $2 \mathrm{~km}$ and the weighted average altitude of the settlement is around $40 \mathrm{~m}$. The village has two entrances on the provincial road that connects Polichnitos with Vatera. One north, as one arrives from the village Polichnitos and in a distance of $6 \mathrm{~km}$ and one south as one arrives from the village of Vatera which is located $2 \mathrm{~km}$ away. 
Some data on the demographic evolution of the settlement are provided $(\mathrm{Ta}$ ble 1). For the Ottoman era they are based on published tax records and travelers' reports, only indicative of accuracy.

The geomorphology of the area is mild, with hilly formations. Only at the base of Mt. Olympus there is a stronger relief. The water basin is mainly leading to the Vatera coast through the two major rivers Almiropotamos and Vourkos. Vrisa has been built south of the stream of Lagada, which is also the northern boundary. Lagada is a tributary of Almiropotamos river, with which it contributes $2 \mathrm{~km}$ west of Vrisa.

The area has an intense geological history, which is embossed in the rocks, but also in places of paleontological finds (Figure 3). Over a 300 million-year-old pro-Balkan substrate, visible at various locations, there are several layers of volcanic sedimentation deposits, and ultimately the post-alpine formations that

Table 1. Demographic data.

\begin{tabular}{|c|c|c|c|c|c|c|c|}
\hline Year & 1548 & 1671 & 1855 & 1882 & 1909 & 1928 & 1940 \\
\hline Population & $\begin{array}{c}235 \\
\text { inhabitants/ } \\
47 \text { houses } \\
\text { of } 5 \text { persons } \\
\text { per house }\end{array}$ & $\begin{array}{c}820 \\
\text { inhabitants/ } \\
164 \text { houses } \\
\text { of } 5 \text { persons } \\
\text { per house }\end{array}$ & $\begin{array}{c}2000 \\
\text { inhabitants/ } \\
\text { Traveler } \\
\text { Information } \\
\text { (Boutan \& } \\
\text { Aristides) }\end{array}$ & $\begin{array}{c}2000 \\
\text { inhabitants }\end{array}$ & $\begin{array}{c}2400 \\
\text { inhabitants/ } \\
480 \text { houses } \\
\text { of } 5 \text { persons } \\
\text { per house }\end{array}$ & $\begin{array}{c}2003 \\
\text { inhabitants } \\
\text { (Including } \\
173 \text { refugees } \\
\text { from Asia } \\
\text { Minor) }\end{array}$ & $\begin{array}{c}1877 \\
\text { inhabi- } \\
\text { tants }\end{array}$ \\
\hline Year & 1951 & 1961 & 1981 & 1991 & 2001 & 2011 & \\
\hline Population & $\begin{array}{c}1735 \\
\text { inhabitants }\end{array}$ & $\begin{array}{c}1658 \\
\text { inhabitants }\end{array}$ & $\begin{array}{c}1179 \\
\text { inhabitants }\end{array}$ & $\begin{array}{c}969 \\
\text { Including } \\
\text { the } \\
\text { inhabitants } \\
\text { of Vatera } \\
\text { village }\end{array}$ & $\begin{array}{l}794 \text { Only } \\
\text { residents of } \\
\text { Vrissa } \\
\text { settlement }\end{array}$ & $\begin{array}{l}617 \text { Only } \\
\text { residents } \\
\text { of Vrissa } \\
\text { settlement }\end{array}$ & \\
\hline
\end{tabular}

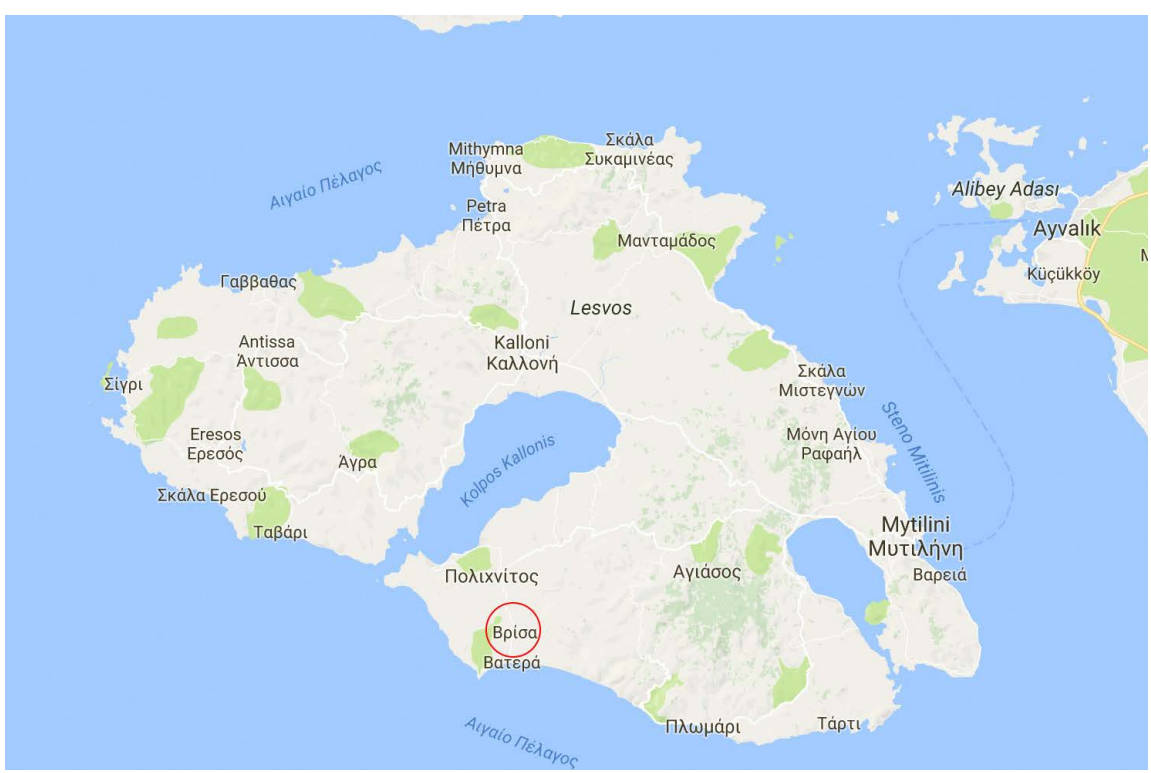

Figure 3. Vrisa, lesbos map. 
cover the entire area of the area and are younger than 23 million years old. These consist of layers of various volcanic handles and sedimentary deposits. The present form of the area is the result of a combination of intense volcanic activity, with continuous deposits of pyroclastic materials and river adhesions.

The backbone of the village is the main road axis, which crosses the settlement by connecting its two entrances, with its central section being the Tsiarsi (market). This road follows a bizarre line in the part from the entrance of the settlement to Platanos Square and becomes smoother but always curved until the other entrance of the village (Figure 4). Its central part is dominated by commercial buildings, while residential buildings dominate its edges. Along the way and from the north to the south there are the following points of reference:

- The old community olive mill (Old Engine), on the north bank of the stream and at the entrance of the village coming from Polichnitos. An important example of industrial heritage. Year of construction: 1892.

- The new Community olive mill (New Machine), on the south bank of the river, just across from the old one, at the entrance of the village by Polichnitos. This is an important example of industrial heritage. Year of construction: 1902.

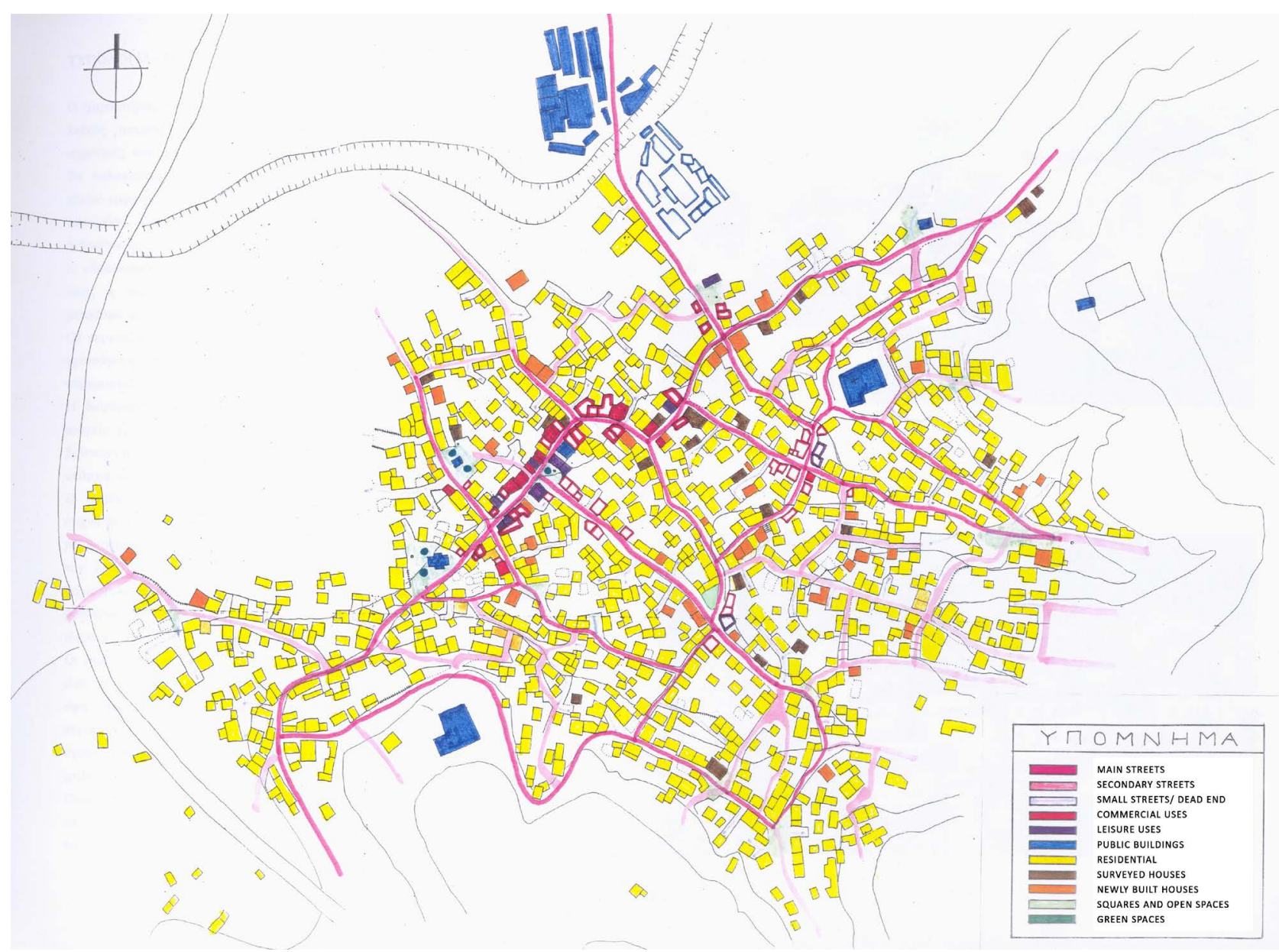

Figure 4. Map of uses. 
- The location of the old Mosque and its preserved marble fount.

- The community building, housed in a two-storey neoclassical building.

- Platanos square, essentially a crossroad with a plane tree and a monolithic well. It is a very typical square because of the views of the cafes and the shops that surround it.

- The plateau of Agia Marina, to the north of the Tsiarsi, with the homonymous church (building sign: 1859) and a well.

- The plateau of Agios Konstantinos with the homonymous neoclassical church (1930), where the old girls' School used to be (1909). It now houses the Natural History Museum where the paleontological finds from the excavations in Vatera are exhibited.

\section{Reconstruction Situation and Regulations after Earthquake}

After the earthquake, there were two researches on the buildings of Vrisa. First time, they were marked by triangle. And at second time, they were marked by cross. The buildings of Vrisa have been marked with red, yellow and green colour in connection to the level of their damage from the earthquake (Figure 5):

- $\quad$ red > not inhabitable-very bad condition-to be demolished

- yellow > not inhabitable- bad condition- to be repaired

- green $>$ good condition-inhabitable

It has a regulation that the government can provide $80 \%$ money to rebuild or repair the buildings and the rest $20 \%$ money can be lent from bank. And each house should be rebuilt in a minimum of $75 \%$ of its total square meters. The reconstruction will cost inhabitants lots of money and it needs a long time, so lots of inhabitants didn't have highly motivation and some of them wanted to sell their houses. Although it is not safe for people to live in house marked in yellow and red, some inhabitants especially old people still live in them. The markets, backery and cinema in Vrisa were all close. Only a café reopened. Children can
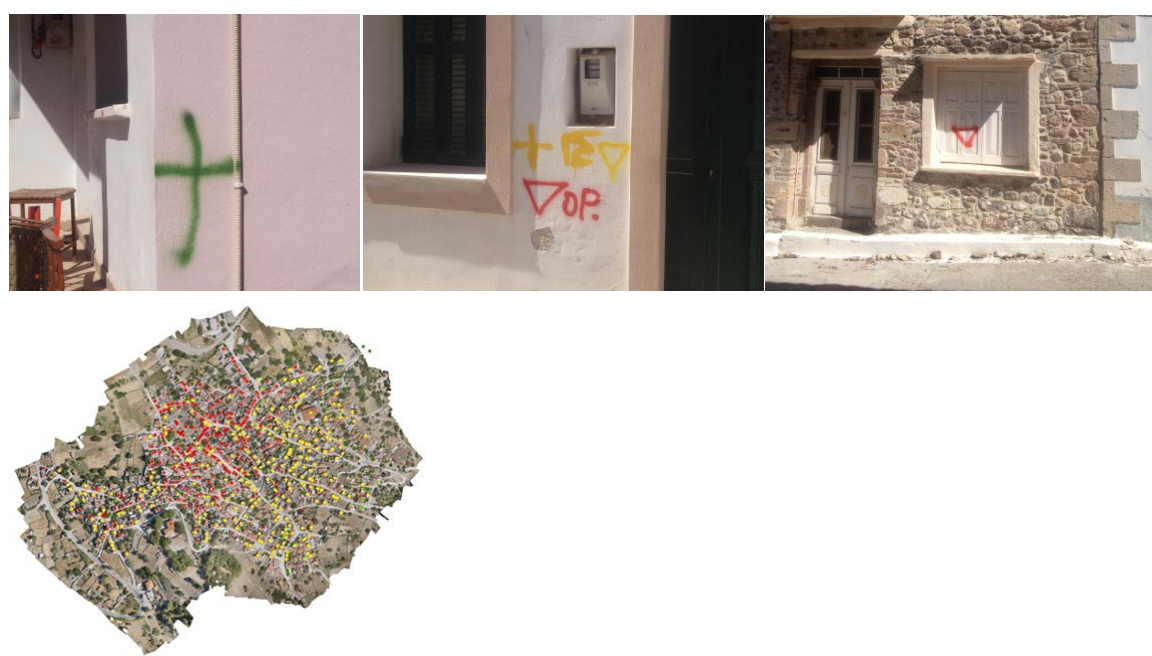

Figure 5. Marked houses in Vrisa. 
study in a temporarily school near the former one.

There are some legal frames for the reconstruction concerning façade, window, door and so on (Figure 6). For instance, the street façade should be continuous and the newly built buildings should use some typical types of windows.

\section{Reconstruction Strategies}

Different inhabitants held different opinions on the reconstruction. Some of them missed the atmosphere of Vrisa and wanted to return to the original condition. And some of them were pessimistic about it. They didn't think the condition would become better in a short time because lots of people left Vrisa and worked in other place. Actually, some houses were abandoned before the earthquake. In my opinion, the most important thing is bringing people back to Vrisa. I have three different strategies to achieve this goal.

\subsection{Activating Uses and Houses}

The first strategy concentrates on the village itself. Before the earthquake, there were many important function buildings like olive oil factories, churches, markets, cafés, bakery and school which can maintain the daily life for inhabitants in Vrisa (Figure 7). Therefore, the first step is activating the uses [3]. In the first phase, the government needs to collect money and rebuild markets, cafés and bakeries that the inhabitants don't need to buy food and commodities in Vatera [4]. It will take about 2 years. In the second phase, they need to rebuild school and olive oil factories. After these, it is more convenient for children to study
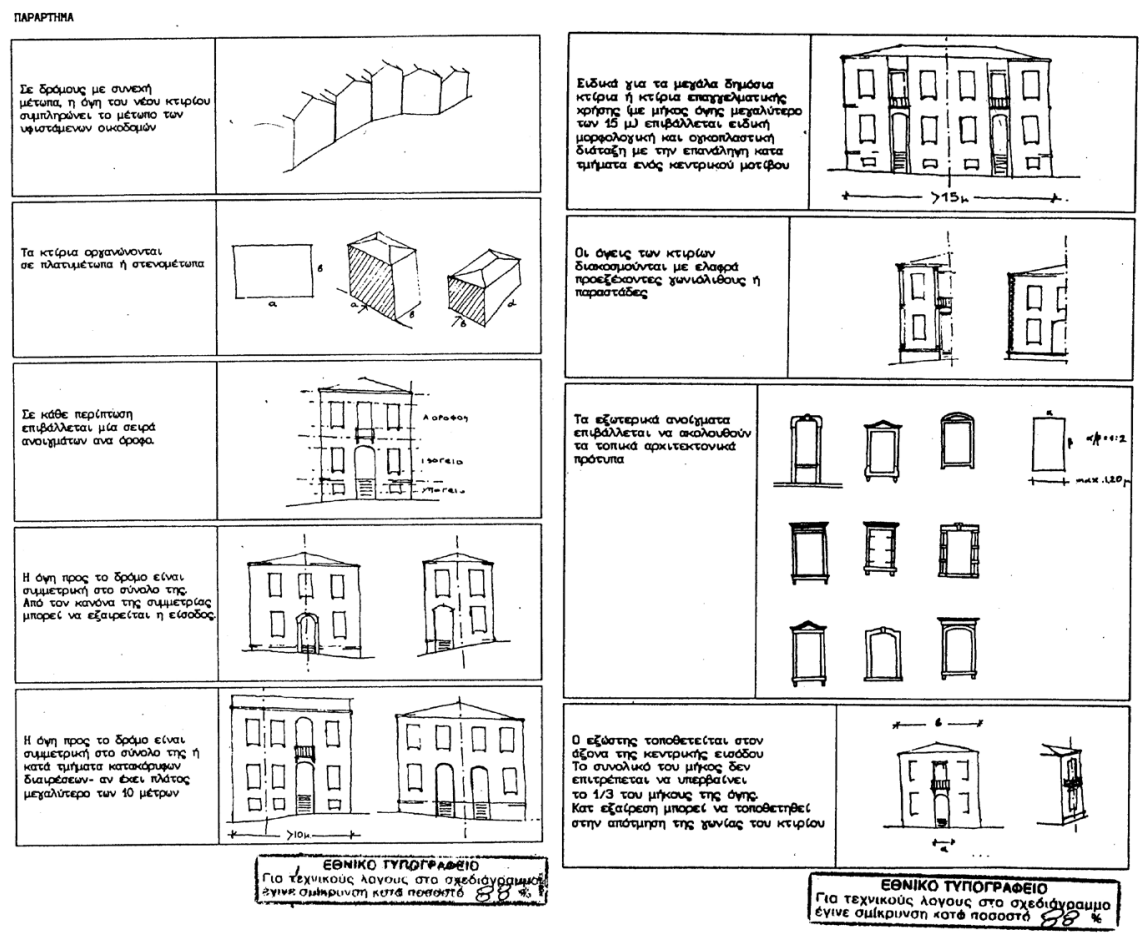

Figure 6. Legal frame. 


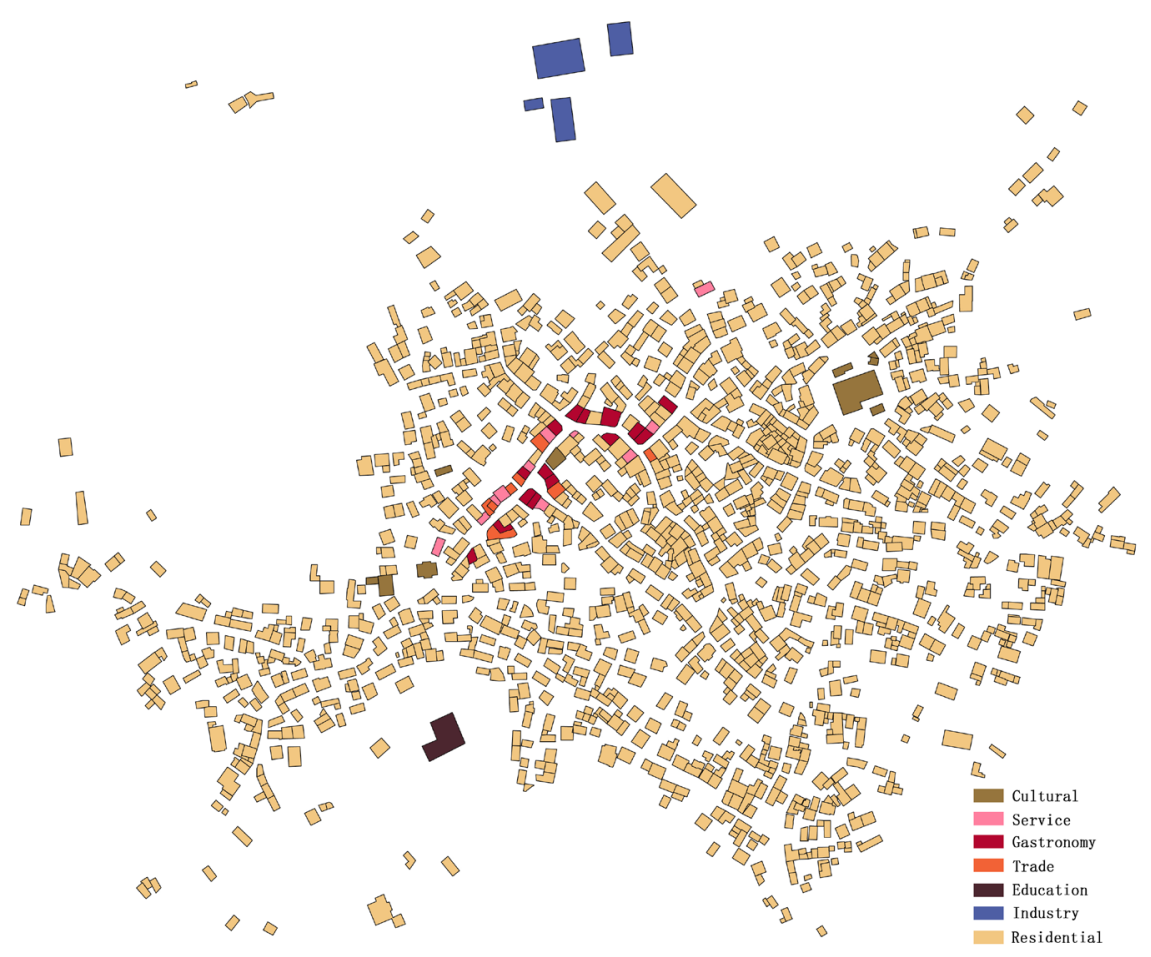

Figure 7. Function buildings.

and the factories will bring job opportunities. In the third phase, they need to rebuild or repair churches and chapels. In total, the first step takes about 5 years.

Then the second step is activating the houses. In the first phase, on the one hand, the government can provide some temporary housing for the inhabitants and put them together in a place near Vrisa; On the other hand, the buildings marked red should be demolished and removed. This phase takes about 4 years. In the second phase, the buildings marked yellow should be repaired and people are supposed to rebuild the demolished houses according to the regulation. The whole process will take almost ten years (Figure 8).

There are three typical types of houses in Vrisa (Figure 9). With the reduction of $25 \%$ square meters, the house type can be different. It need to be considered.

\subsection{Combining with Vatera and Polichnitos}

The second strategy is combining with Vatera and Polichnitos to develop together. Exploit the advantages of these three places to the full. Take these three places as three point of interests (Figure 10).

Polichnitos has good hot springs; Vatera has a long coastline that people can enjoy swimming and eating sea food there. As for Vrisa, it has two abandoned factories and a tower. It can be used as museum in a record of earthquake. The three places can be used to plan a tour route and attract many tourists.

\subsection{Resettlement of Refugees}

The island Lesbos has a strategic position (Figure 11). It is an informal gate of 


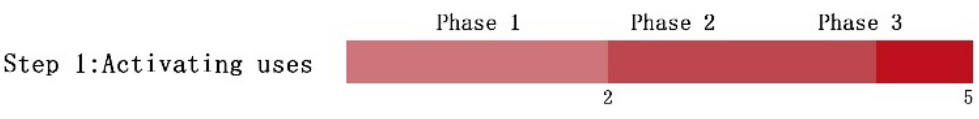

Step 2:Activating houses

Figure 8. Timeline of reconstruction.

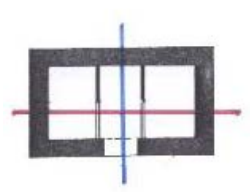

Type A

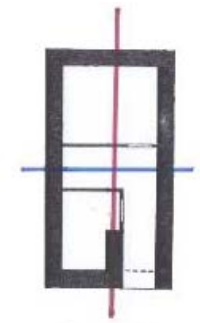

Type B

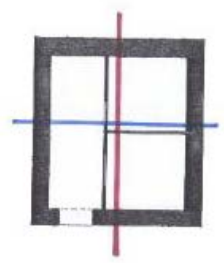

Type C

Figure 9. Three typical houses in Vrisa.

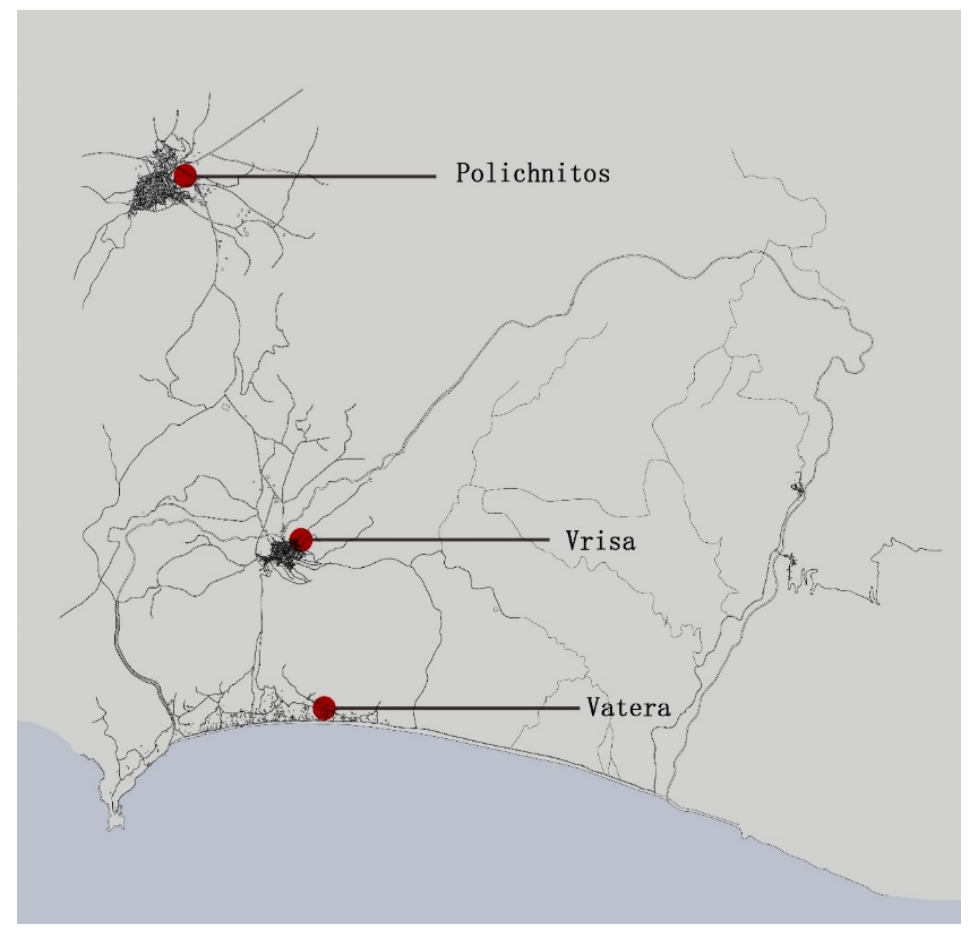

Figure 10. Location of Vrisa, Vatera and Polichnitos.

Europe that lots of refugees chose it as an entry point. The thousands of refugees and informal migrants from Syria, Afghanistan, Iran, Pakistan and Somalia who arrive in Skala, Lesbos on a daily basis, are eventually transported to the official centers of registration where they are divided into those entitled to refugee status and the subsequent right to continue their journey [5].

A large number of refugees are homeless so they stayed in the squares of Lesbos (Figure 12). This is a big issue and can't be solved in a short time. It has bad influence on city image, public security, economy and other aspects. The third 


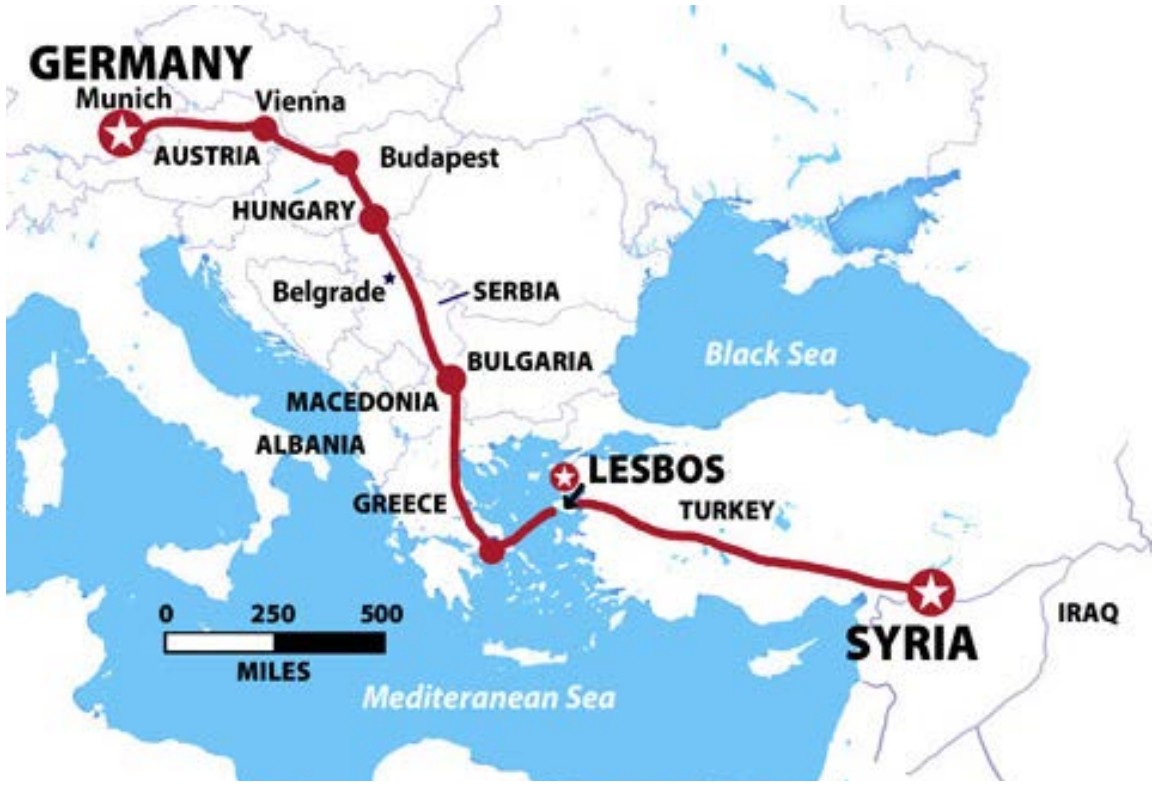

Figure 11. Migration route of refugees.

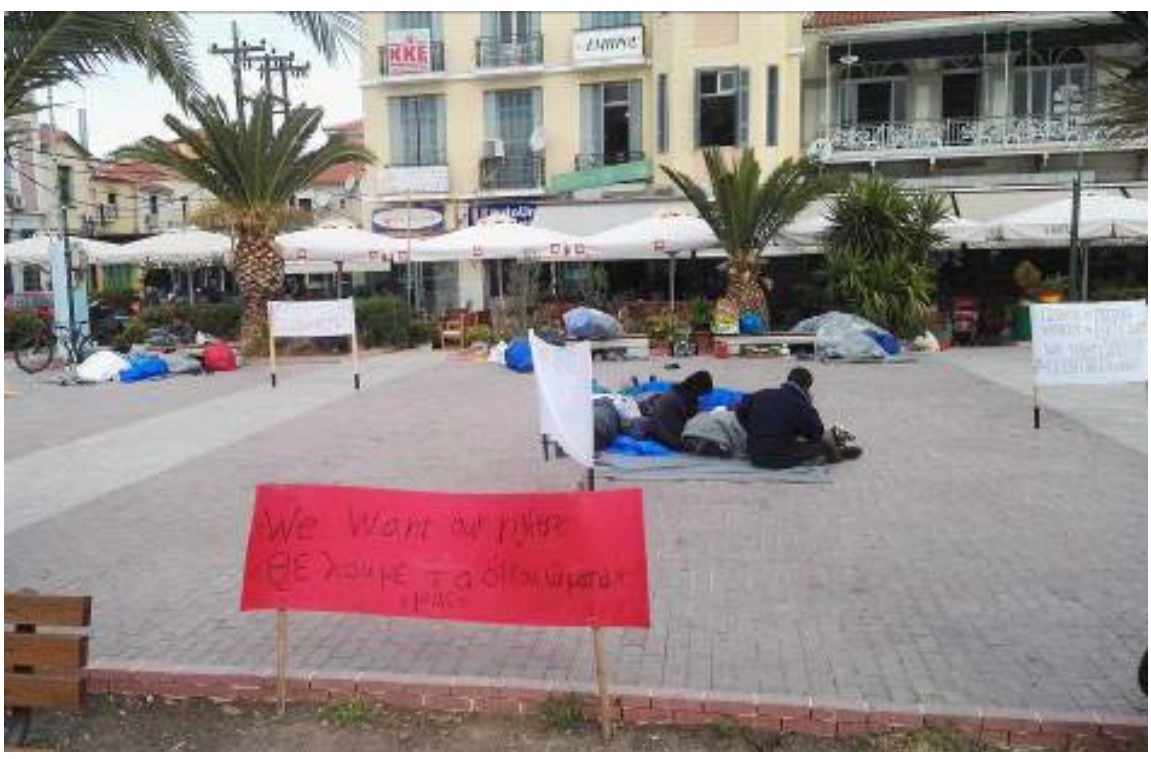

Figure 12. Refugees in Lesbos island.

strategy is use Vrisa as resettlement place for refugees. If the original inhabitants don't want to live in Vrisa any more, it can provided houses for refugees to live [6].

\section{Conclusion}

Based on the above explanations, it could be concluded that Vrisa has many difficulties in reconstruction temporarily and it will take a long process. According to interviews on the inhabitants, most of them want to rebuild the village and live there after reconstruction. Therefore, these points need to be seriously considered. At first, the reconstruction and transformation methods are the most 
significant issues like how to deal with the red, yellow and green houses. Then, they should arrange the time to rebuild the function buildings and houses. And an important problem is how to get enough money and funding to finish the reconstruction. Furthermore, as a new regulation defines the rebuilding of each house in a minimum of $75 \%$ of its total square meters, the house type should be redesigned.

\section{Funded}

Funded by the China Natural Science Foundation (Award Reference: 51678241) and the State Key Laboratory of Subtropical Building Science Innovation Foundation (Award Reference: 2017KB08).

\section{References}

[1] Alexander, D. (2006) Globalization of Disaster: Trends, Problems, and Dilemmas. Journal of International Affairs, 59, 123.

[2] Pelling, M. (2003) Natural Disasters and Development in a Globalizing World. Routledge, London.

[3] Ikaputra, I. (2006) People Response to Localize the Imported Culture, Study Case: the Dome House in the Rural Culture Post Javanese Earthquake. iitk <iitk.ac.in/>

[4] Harvey, P. Towards Good Humanitarian Government: The Role of the Affected State in Disaster Response. <odi.org.uk>

[5] Papataxiarchis, E. Being "There" at the Front Line of the "European Refugee Crisis". Anthropology Today, 32, 5-9. https://doi.org/10.1111/1467-8322.12237

[6] Farabi, N. and Susiatiningsih, H. (2016) Communication Strategies of DFTW (Domes for the World) in Post-Earthquake Reconstruction and Rehabilitation in Yogyakarta, Indonesia. ICPM, 127-128. https://doi.org/10.2991/icpm-16.2016.36 